\title{
Clinical Practice of Hepatorenal Syndrome: A Brief Review on Diagnosis and Management
}

\author{
Rendy, Febyan, and Krisnhaliani Wetarini
}

\section{ABSTRACT}

\begin{abstract}
The hepatorenal syndrome is one of various potential causes of acute kidney injury in patients with decompensated liver disease. Hepatorenal syndrome is diagnosed based on reducing kidney function without any evidence of intrinsic kidney disease, including proteinuria, hematuria, or abnormal kidney ultrasonography. Clinically, hepatorenal syndrome is divided into two types named type 1 and type 2 . The most favorable therapy for HRS cases is liver transplantation; however, only a few undergo this procedure due to the high mortality. Other modalities for hepatorenal syndrome therapy are pharmacology and non-pharmacology approaches. The purpose of management HRS is to optimize and stabilize the patient until an organ transplant available. This review aims to discuss the underlying pathophysiology and demonstrate the diagnostic approach of hepatorenal syndrome to determine the most appropriate therapeutic measures in clinical practice. The clinicians must be aware of management principles of hepatorenal syndrome to improve the quality of care for patients and optimize the clinical conditions.
\end{abstract}

Keywords: Hepatorenal syndrome, diagnosis, management, clinical approach.

\section{INTRODUCTION}

Hepatorenal syndrome (HRS) was first explained in 1932 to describe renal failure that caused by biliary tract surgery; but, in 1862, HRS was introduced as renal dysfunction in patients with advanced liver disease [1], [2]. Globally, HRS is known as life-threatening condition that caused a significant socioeconomic burden on affected individuals and healthcare systems [3]. In the United States, HRS affects over 633,000 adults each year [4]. It also represents the sixth most common cause of death due to non-communicable diseases worldwide [5]. Meanwhile, in Europe, HRS is responsible for 170,000 deaths each year, with wide variations between countries [6]. Hepatorenal syndrome usually presents as a complication in patients with decompensated liver cirrhosis, causing conditions called portal hypertension and a severe form of acute kidney injury (AKI) [4]. Many cases of HRS are over-diagnosed, and more than half are potentially preventable early. This review is aimed to discuss the diagnosis, pathogenesis, and management comprehensively to prevent any mistake of diagnosis and management for the patient with hepatorenal syndrome.

\section{DEFINITION}

Hepatorenal syndrome is a functional form of acute kidney injury (AKI) characterized by renal vasoconstriction [7]. Many studies have explained that HRS can be defined into four types (see Table I).
Submitted : February 26, 2021

Published : March 23, 2021

ISSN: $2593-8339$

DOI: 10.24018 /ejmed.2021.3.2.743

Rendy *

Department of Medicine, Kalideres

General Hospital, Jakarta, Indonesia.

(e-mail: rendyrendydr@gmail.com)

Febyan

Department of Medicine, Metro

Jababeka Hospital, Cikarang,

Indonesia.

K. Wetarini

Department of Medicine, Garbamed Hospital, Bali, Indonesia.

*rendyrendydr@gmail.com
TABLE I: CLASSIFICATION OF HEPATORENAL SYNDROME [7], [8]

\begin{tabular}{cl}
\hline \hline Types of Hepatorenal Syndrome & \multicolumn{1}{c}{ Findings } \\
\hline Type 1 & $\begin{array}{l}\text { Cirrhosis by rapidly progressive } \\
\text { acute renal failure* }\end{array}$ \\
Type 2 & $\begin{array}{l}\text { Cirrhosis by subacute renal } \\
\text { failure }\end{array}$ \\
Cirrhosis with type-1 or 2 HRS \\
Type 3 \\
superimposed by chronic kidney \\
disease or acute renal injury
\end{tabular}

No study has determined the clinical characteristics, natural history, and laboratory features of type- 3 and 4 HRS.

* As recently redefined by the International Ascites Club.

$\dagger$ Chronic kidney diseases such as chronic glomerulonephritis, hypertensive nephropathy, diabetic nephropathy, etc. Acute renal injury includes acute tubular necrosis and other causes.

Recent studies classified HRS into two types. Type 1 HRS is explained by a rapid and progressive reduction in renal function, defined as the doubling of initial serum creatinine to a level more than $2.5 \mathrm{mg} / \mathrm{dL}$ or a decrease in half of the initial 24-hour creatinine clearance to a level lower than 20 $\mathrm{mL}$ per minute in less 14 days. Contrary, type 2 HRS does not present a rapidly progressive disease course and is commonly associated with mortality among patients who do not die of other complications of cirrhosis [9].

\section{PATHOGENESIS}

The main pathogenesis of decreased renal blood flow in HRS patients is due to vasoconstriction of renal microcirculation related to neurohumoral effects, activation of the renin-angiotensin-aldosterone system (RAAS), 
activation of the sympathetic nervous system, natriuretic peptide, and endothelin [10]. Renal system deterioration in a patient with liver damage appears to be due to unknown nephrotoxins, which are no longer eliminated and metabolized by the liver [10]. Peripheral arterial vasodilatation is reasonable mechanism to explain the pathogenesis of HRS. It starts due to decreased of vascularization from splanchnic, which occurs as a result of portal hypertension from cirrhosis as the initiating factors in the development of HRS. Splanchnic vasodilatation is biochemically mediated by nitric oxide, monoxide, glucagon, and other vasodilators [8].

In compensated cirrhosis, cardiac contractility may increase to counterbalance systemic vascular resistance (low circulation condition). Based on this pathogenesis, effective arterial volume should be monitored. Reversely, in end stage cirrhosis, cardiac contractility no longer copes because of the effects from cirrhotic cardiomyopathy development. When arterial blood volume decreases, sympathetic nervous system and arginine vasopressin, compensator neuromuscular vasoconstrictor system like RAAS are stimulated. This condition may cause the retention of water and sodium, resulting to ascites and hyponatremia, as well as renal and cerebral vasoconstriction in the peripheral vascular bed.
Moreover, Prostaglandins as local renal vasodilators are initially able to counterbalance the effects of the vasoconstrictor neurohormonal system. However, this condition will eventually complicate the renal blood flow and subsequently decreasing glomerular filtration rate and fall to HRS symptoms (see Fig. 1) [11], [12].

Secondary vasodilation due to portal hypertension may occurs in decompensated cirrhosis, followed by activation of inflammation that induced by gastrointestinal bacterial translocation. It induces kidney arterial vasoconstriction by the enzyme systems activation in response to reduced effective blood volume and kidney inflammation because the presence of microvascular changes. These changes turn to increased cardiac output, ascites, and normal GFR limit, but increase susceptibility of the kidney to AKI (see Fig. 1 (A)). The onset of HRS corresponds to the most advanced stages of these changes, with an intense renal vasoconstriction and impaired renal autoregulation that leads to a decrease in GFR (see Fig. 1 (B)). Any events further causing hypovolemia, including diuretics overdose, lactulose induced diarrhea, bleeding; decreased cardiac output, initiated by non-selective beta-blockers and cirrhotic cardiomyopathy; as well as systemic inflammation with or without sepsis, are also the variety of conditions that may cause HRS [12]-[15].
A

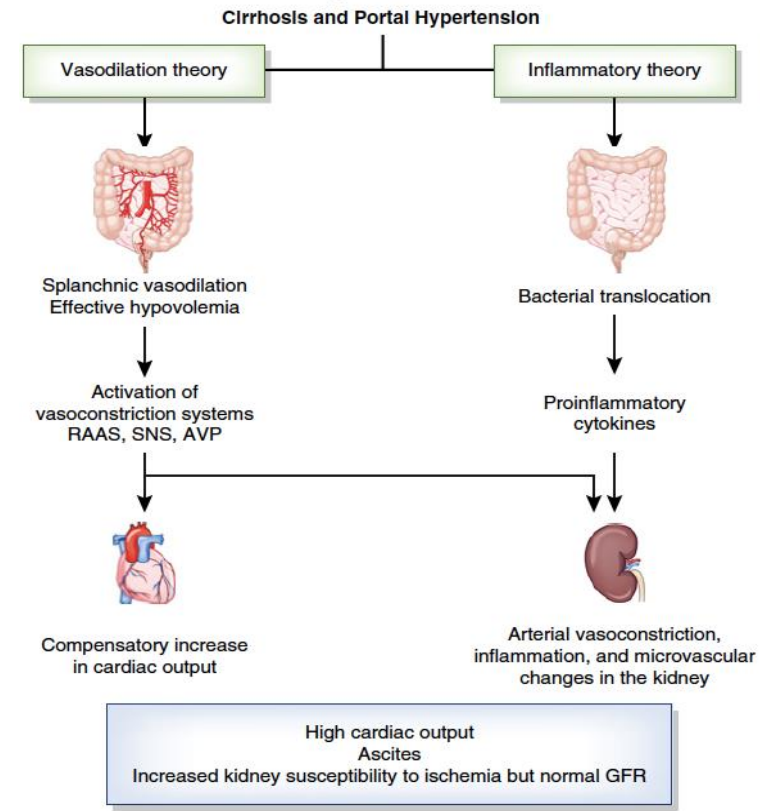

B

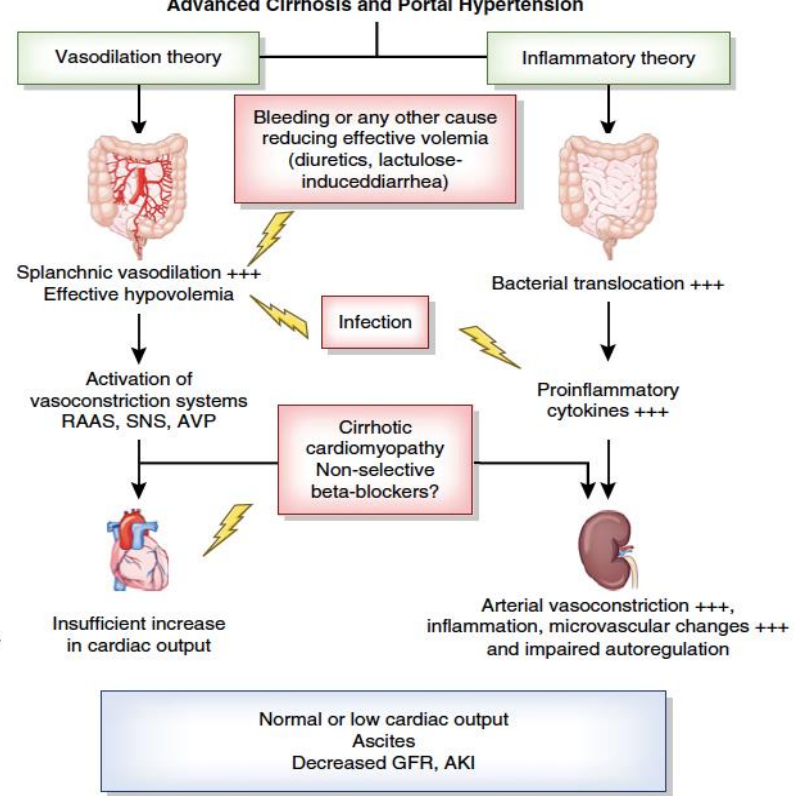

Fig. 1. Relationship of HRS [12], [15].

\section{DIAGNOSIS}

The diagnosis of exclusion is considered in HRS [13], [14]. Therefore, the first step in its diagnosis is to exclude the presence of structural kidney injury (see Table II).

The criteria of HRS have been improved throughout the years. International Ascites Club (IAC) in 1996 defined the minor and major criteria to characterize the pathology finding of renal failure in cirrhotic patients [16]. Major criteria such as, liver failure, portal hypertension based on clinical findings, and AKI, while excepting shock, hypovolemia, ongoing sepsis, nephrotoxic drug, nephrotic syndrome, and obstructive uropathy [17]. Meanwhile, the minor criteria consist of lower urinary output, changing of sodium osmolality profile, red blood cells, and serum sodium parameters. in 2007, all the criteria were revised to improve accuracy, excluding minor criteria, but including ongoing bacterial infection without any shock by sepsis [7], [18]. Based on the IAC criteria, acute renal failure is remarks as a quantitative rise in serum creatinine $(\mathrm{sCr})$ of a half percent from baseline to a final value more than $1.5 \mathrm{mg} / \mathrm{dL}$ (133 mol/L). Meanwhile, a new consensus explained that of acute renal failure, now termed acute kidney injury (AKI), has been validated in patients without cirrhosis. [15]. Based 
on new guideline, $\mathrm{AKI}$ is defined by quantitative $\mathrm{sCr}$ rise of $0.3 \mathrm{mg} / \mathrm{dL}(26.5 \mu \mathrm{mol} / \mathrm{L})$ in 2 days or a half percent from baseline within 1 weeks. There are three stages classification of AKI and treatment parameters were outlined. The new criteria allow earlier treatment, having to a better outcome instead of waiting until the $\mathrm{sCr}$ reaches $2.5 \mathrm{mg} / \mathrm{dL}$ [19], [20]. Thereby, the differential diagnosis of HRS (see Table III). Type 1 HRS is not the only type of AKI that can complicate cirrhosis; making an accurate differential diagnosis becomes the key in determining the most appropriate treatment. Acute kidney injury occurs in approximately two-thirds of the cases are prerenal, of which the majority correspond to prerenal azotemia.

TABLE II: DIAGNOSTIC CRITERIA OF HEPATORENAL SYNDROME BASED ON INTERNATIONAL CLUB OF ASCITES-ACUTE KIDNEY INJURY [14], [15] Criteria

1. The presence of cirrhosis with ascites

2. Presence of AKI based on ICA-AKI criteria

3. No improvement of serum creatinine ${ }^{*}$ after two consecutive days of diuretic withdrawal and expansion of plasma volume using albumin $(1 \mathrm{~g} / \mathrm{kg}$ body weight/day up to a maximum of $100 \mathrm{~g} / \mathrm{d})$

4. Absence of shock

5. Absence use of nephrotoxic drugs ${ }^{\dagger}$

6. No macroscopic features of structural kidney injury ${ }^{\ddagger}$

* At least decrease to a level of $1.5 \mathrm{mg} / \mathrm{dL}$ or less).

$\dagger$ Some of the nephrotoxic drugs are aminoglycosides, iodinated contrast media, non-steroidal anti-inflammatory drugs, etc.

$\$$ No proteinuria (> $500 \mathrm{mg} / \mathrm{d}$ ), No microhematuria (> 50 red blood cells per high power field), and renal ultrasound revealed normally.

TABLE III: THE DIFFERENTIAL DIAGNOSIS OF HRS BASED ON LABORATORY EXAMINATION AND THERAPY RESPONSE [20]

\begin{tabular}{cccc}
\hline \multicolumn{4}{c}{ LABORATORY EXAMINATION AND THERAPY RESPONSE [20] } \\
\hline Criteria & $\begin{array}{c}\text { Prerenal } \\
\text { failure }\end{array}$ & $\begin{array}{c}\text { Hepatorenal } \\
\text { syndrome }\end{array}$ & $\begin{array}{c}\text { Acute tubular } \\
\text { necrosis }\end{array}$ \\
\hline $\begin{array}{c}\text { Urinary/plasma } \\
\text { osmolarity }\end{array}$ & $>1$ & $>1$ & $<1$ \\
$\begin{array}{c}\text { Sodium excretion } \\
\text { fraction }\end{array}$ & $<1$ & $<1$ & $>1$ \\
$\begin{array}{c}\text { Urinary Na/mEq/L } \\
\text { Response to fluid } \\
\text { expansion }\end{array}$ & $<10$ & $<10$ & $>30$ \\
\hline \hline
\end{tabular}

\section{BIOMARKER}

Many studies have shown that various biomarkers such as neutrophil gelatinase-associated lipocalin (NGAL), interleukin-18 (IL-18) and kidney injury molecule-1 (KIM1), epidermal growth factor (EGF), adrenomedullin uromodulin (UMOD), toll-like receptor-4 (TLR-4) and other urine markers including albuminuria and fractional excretion of sodium $(\mathrm{FeNa})$ may be considered in HRS diagnosis. In other cases, IL-18, KIM-1, and NGAL may diagnose AKI earlier to differentiate acute tubular necrosis from HRS [21]. Albuminuria is an indicator of kidney injury and also significantly dominantly in ATN. Precise cut-off values are still needed, and more studies should be explored to understand better the relationship of albuminuria and glomerular changes in HRS, and liver dysfunction [22]. Fractional excretion of sodium is reduced in HRS. Theoretically, FeNa $<1 \%$ or $>1 \%$ can be consider evaluating between HRS and intrinsic renal dysfunctions. Alsaad and colleagues mentioned that $\mathrm{FeNa}<1 \%$ in HRS was not accurate. But the test had high sensitivity and high negative predictive value, indicating that HRS diagnosis can be excluded in patients with negative test results (if $\mathrm{FeNa}$ more than $1 \%$ ) [23].

\section{MANAGEMENT}

The definitive and widely recognizable treatment of HRS is liver transplantation. However, it is not immediately available, so that other treatment modalities are considered to reduce mortality and stabilize clinical conditions until liver transplantation is available [10]-[14]. Hepatorenal syndrome may develop in the setting of advanced liver disease and acute liver failure. Both cases present volatile conditions requiring hospitalization, preferably in an intensive care unit for type 1 HRS patients. Continuous monitoring by vital signs, fluid monitoring, daily weights, and urinary output should be considered. Central line access with central venous pressure measurement may help in monitoring volume status in HRS patients. The most accepted HRS management includes splanchnic vasoconstrictors agents, portosystemic shunts, and organ transplantation (see Table IV) [24].

\section{A. Pharmacological Therapy}

\section{Vasoconstrictors and Albumin}

There are three modalities' drugs as vasoconstrictors, such as: (a) norepinephrine (NE) and midodrine (alpha-adrenergic agonists) that act to constrict the smooth muscle and increase systemic vascular resistance; (b) terlipressin and ornipressin (vasopressin agents) that induce smooth muscle vasoconstriction and decrease portal pressure; (c) octreotide (somatostatin agents) that may inhibit the release of systemic vasodilators [25]. These three vasoconstrictors should be mixed with human albumin infusion given at a dose of 20$40 \mathrm{~g} /$ day [26]. Many studies reported that a combination of alpha-adrenergic agents, vasopressin-like vasoconstrictors, and albumin are first of choice in HRS. These agents may increase systolic blood pressure and the arterial volume, that induced increasing renal perfusion and splanchnic vasoconstriction effects [25]. Piano and colleagues stated that terlipressin combination with albumin improved HRS by $50 \%$ and increased survival [27]. Many factors are associated with HRS reversal, such as decrease serum bilirubin, lower $\mathrm{sCr}$ at the first of the medications, and a more extended grade of acute on chronic liver failure [20].

\section{Other Vasoconstrictors}

The clinicians should consider other vasoconstrictors agents if terlipressin is not available. Sole and colleagues stated that $\mathrm{NE}$ is as effective than terlipressin in HRS management [26]. However, it needs to be administered under continuous monitoring in a critical care unit. Cavallin and colleagues reported that the combination of midodrine plus octreotide with albumin infusion might be effective enough. Still, another study has proven that this combination is less effective than terlipressin [28]. A pharmacological study by Wang and colleagues reported that terlipressin combined with albumin and dopamine with furosemide and albumin should be considered to reduce $\mathrm{sCr}$; octreotide combination with midodrine plus albumin was the most effective to improving serum sodium [29].

\section{Antibiotics}

Hepatorenal Syndrome patients have a high chance of bacterial infection or spontaneous bacterial peritonitis (SBP); however, antibiotics are administered if clinicians have found 
infection sign or a high suspicion of infection. Prophylactic antibiotics are not recommended unless a bacterial infection is confirmed by blood, urine, or ascites culture [30].

\section{B. Non-Pharmacological Therapy}

\section{Liver Transplant}

A liver transplant is the treatment of choice because it represents the definitive treatment for HRS patients. The clinicians should consider this treatment when a poor prognosis is present. On the other hand, liver transplantation alone is preferred only to simultaneous liver and kidney transplantation because HRS is reversible with liver transplantation in most cases [31].

\section{Molecular Adsorbent Recirculating System}

The mechanism of this approach is a form of albumin dialysis whereby albumin is recirculated repeatedly to adsorb various bacterial products and cytokines that are thought to be responsible for maintaining the vasodilatory state of advanced cirrhosis. Mitzner and colleagues reported that molecular adsorbent recirculating system in HRS treatment may reduce a $\mathrm{sCr}$ and mortality rate [32]. A randomized controlled trial by Bannares and colleagues observed 189 HRS patients, with $50 \%$ type 1 , have lower in $\mathrm{sCr}$ after received a molecular adsorbent recirculating system than standard medical treatment. However, there was no benefits on 28-day survival, irrespective of whether the entire study population or the subgroup of patients with type 1 HRS was evaluated [33]. Recent clinical guidelines from EASL explained that a molecular adsorbent recirculating system is not fully understood for HRS patient treatment [34].

\section{Transjugular Intrahepatic Portosystemic Shunt (TIPS)}

Transjugular intrahepatic portosystemic shunt is aimed to lower portal hypertension and reversing the circulatory changes that precipitate HRS, thus allowing kidney function to restore physiologically. Song and colleagues showed that TIPS is associated with decreased serum creatinine, with possible survival benefits in HRS patients [35]. Charilaou and colleagues have performed a retrospective analysis of the National Inpatient Sample database from 2005 to 2014 using ICD-9-CM codes to identify patients with HRS who received treatment with TIPS, compared the outcome of these patients with those who received dialysis or no TIPS, they found that TIPS is more superior associated with reducing inpatient mortality rate [36].

\section{Renal Replacement Therapy (RRT)}

Theoretically, this approach may be considered for HRS patients. The indications for RRT are not different for AKI patients without cirrhosis. Renal replacement therapy is among the so-called bridging therapies designed to support patients awaiting liver transplants [37]. There is a preference for continuous RRT over intermittent hemodialysis in hemodynamically unstable patients [38]. According to EASL, RRT may be useful for HRS patients who failed vasoconstrictor therapy and fulfill renal support criteria [39].

\section{Nutritional Treatment}

Malnutrition is commonly seen in HRS patients and has been shown to affect the outcome adversely. Chang and colleagues have reported that HRS patients induced by hepatitis B induced acute-on-chronic liver failure have insufficient nutritional intake and a high nutritional risk of impaired intestinal barrier function [40]. Some mechanisms contribute to malnutrition in HRS, including malabsorption, inadequate dietary intake, increased intestinal protein losses, low protein synthesis, substrate utilization disturbances, and hypermetabolism. Unfortunately, these mechanisms are not fully understood [41]. A prospective cohort multicenter study from Korean Nationwide, done by Park and colleagues, showed that long-term supplementation of oral branchedchain amino acids (BCAAs) could potentially improve liver function and reduced major complications of HRS patients (HR=0.389, 95\% CI=0.221-0.684, $p$-value <0.001) [42]. In general management for HRS patients, salt intake should be maintained, which is recommended that restricting salt intake to $80-120 \mathrm{mmol} / \mathrm{day}$, while fluid intake is not restricted [43].

TABLE IV: STUDIES RECOMMENDATIONS FOR MANAGEMENT OF HRS PATIENT

\begin{tabular}{|c|c|c|c|}
\hline No. & Studies & Years & "Recommendations \\
\hline 1. & ASSLD [9] & 2012 & $\begin{array}{l}\text { - Neutrophil gelatinase can be considered as urinary biomarkers in the differential diagnosis of azotemia in patients with } \\
\text { cirrhosis. (Class IIa, Level B) } \\
\text { - Albumin infusion plus octreotide and midodrine should be considered for type } 1 \text { HRS. (Class IIa, Level B) } \\
\text { - Albumin infusion combined with NE should be considered for type } 1 \text { HRS in the Intensive Care Unit setting. (Class } \\
\text { IIa, Level A) } \\
\text { - Liver transplantation should be considered for the patient with cirrhosis, ascites, and type } 1 \text { or type } 2 \text { HRS. (Class I, } \\
\text { Level B) }\end{array}$ \\
\hline 2. & $\begin{array}{l}\text { Acevedo and } \\
\text { colleagues } \\
\quad[44]\end{array}$ & 2017 & $\begin{array}{l}\text { - Terlipressin should be considered at } 2 \mathrm{mg} / \mathrm{day} \text { in continuous infusion, diluted in } 250 \mathrm{~mL} \text { of Dextrose } 5 \% \text { along with } \\
\text { albumin (20-40 g/day), assessed for the therapy response every } 48 \text { hours. An increase in a stepwise manner of } \\
\text { terlipressin is needed (increase in } 2 \mathrm{mg} / \text { day) if no response at the first step. } \\
\text { - Observation for the circulation such as acral parts as ischemic side effects, ischemic heart events, bowel ischemic } \\
\text { (diarrhea), heart electrocardiography (arrhythmias), and electrolyte imbalance (hyponatremia) Albumin infusion plus } \\
\text { octreotide and midodrine should be considered for type } 1 \mathrm{HRS} \text {. (Class IIa, Level B) }\end{array}$ \\
\hline 3. & $\begin{array}{l}\text { Angeli and } \\
\text { colleagues } \\
{[45]}\end{array}$ & 2019 & $\begin{array}{l}\text { - Terlipressin can be given by intravenous boluses at } 0.5-1 \mathrm{mg} \text { every } 4-6 \text { hours to a maximum dose of } 2 \text { mg every } 4 \text { hours. } \\
\text { - Continuous intravenous infusions start from } 2 \mathrm{mg} / \mathrm{day} \text { to a maximum dose of } 12 \mathrm{mg} / \mathrm{day} \text {. Thorough clinical screening } \\
\text { is advised prior to the treatment, with close monitoring for the patients need to be continued along with treatment } \\
\text { duration. } \\
\text { - After discontinuation, a recurrence of HRS may be observed in less than } 20 \% \text { of patients with type } 1 \mathrm{HRS} \text {, and } \\
\text { retreatment is usually effective. }\end{array}$ \\
\hline 4. & $\begin{array}{l}\text { Chmielewski } \\
\text { and colleagues } \\
{[46]}\end{array}$ & 2018 & $\begin{array}{l}\text { - Combination midodrine and octreotide may be considered at starting dose of midodrine is } 7.5 \mathrm{mg} \text { thrice daily titrated } \\
\text { to } 12.5 \mathrm{mg} \text { three times daily in conjunction with } 100 \text { to } 200 \mu \mathrm{g} \text { of subcutaneous octreotide. } \\
\text { - Midodrine and octreotide are also used in combination with albumin administration. }\end{array}$ \\
\hline 5. & EASL [39] & 2010 & $\begin{array}{l}\text { - Less severe liver disease with gastrointestinal bleeding has a higher risk for SBP. It is recommended to given antibiotics } \\
\text { including norfloxacin as selective intestinal decontamination, starting dose of } 400 \mathrm{mg} / 12 \text { hours orally for seven days. } \\
\text { - Ceftriaxone intravenous is recommended for HRS patients with gastrointestinal bleeding and severe liver disease. }\end{array}$ \\
\hline
\end{tabular}




\section{New Algorithm for the Treatment of AKI-HRS}

The management for HRS based on the new diagnostic criteria that focused on AKI (see Fig. 2). Acute kidney injury is diagnosed, the etiology of AKI should be investigated as soon as possible to prevent AKI progression. However, even in the absence of a definitive recognized cause, AKI treatment should be immediately started according to the initial stage [40]-[45]. Irrespective of the stage, diuretics and beta-blockers should be discontinued or tapered, including screening and treatment of infections, volume expansion if necessary, and discontinuation of all nephrotoxic agents, such as vasodilators, beta-blockers, or non-steroidal antiinflammation drugs (NSAIDs) [46].

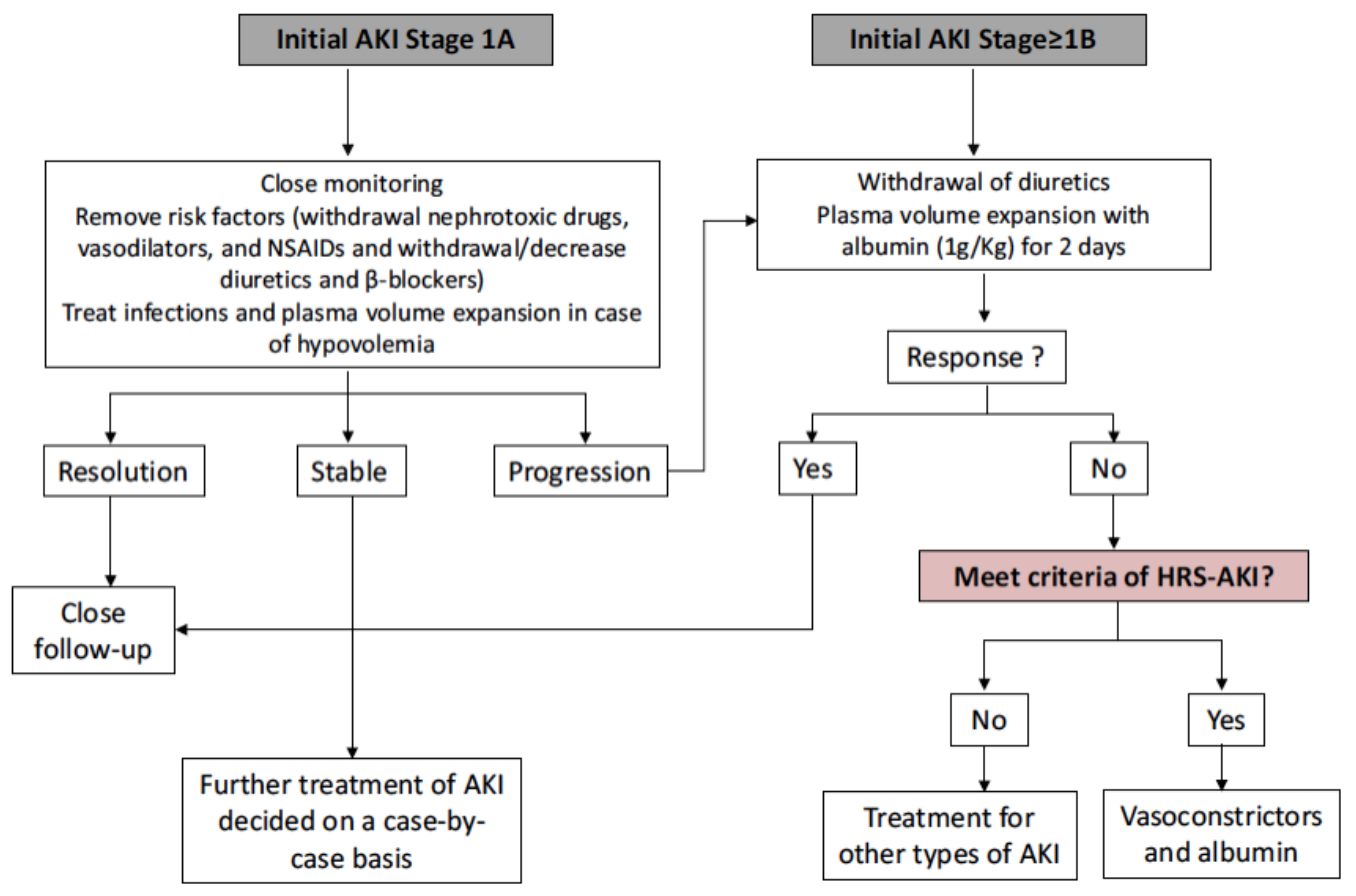

Fig. 2. Management algorithm of acute kidney injury with HRS [45].

\section{PROGNOSIS}

Prognosis is poor when patients with cirrhosis advancing renal impairment, and HRS is correlated with the worst mortality between various causes of AKI in cirrhosis settings [37]. Alessandria and colleagues found that the median survival times as one month and six months in type 1 and type 2 HRS, respectively [47]. More prognostic studies with the updated revision on HRS diagnostic criteria will be required. Appenrodt and colleagues reported that the prognosis of HRS having median survival time of 2-10 weeks for type $1 \mathrm{HRS}$ and 3-6 months for type 2 HRS [48]. The other study in 20022012 found that HRS patients had the higher incidence of complications such as SBP, coma, bleeding. Furthermore, HRS patients underwent more procedures such as renal dialysis, TIPS, and liver transplantation. Overall, the longterm outcome was worse in HRS patients, and the adjusted mortality rate was $32 \%$ with HRS vs. $10.3 \%$ without HRS. Moreover, the median hospital length of stay was 7 vs. 5 days, and hospital costs were higher [49]. Alessandria and colleagues identified a low survival at three months; based included serum bilirubin $\geq 3 \mathrm{mg} / \mathrm{dL}$, MALD score $\geq 20$, prothrombin time $\geq 60 \%$ of normal level, Child-TurcottePugh score $>10$, blood urea nitrogen $\geq 60 \mathrm{mg} / \mathrm{dL}$, serum creatinine $>2 \mathrm{mg} / \mathrm{dL}$, serum sodium $\leq 130 \mathrm{mEq} / \mathrm{L}$, and type 1 HRS. [47] On the other hand, liver transplantation is believed as preferred treatment for HRS. However, the majority of patients die before an organ is higher [50].

\section{PREVENTION}

Consideration of HRS prevention is the most important since it develops with a constant frequency in SBP and alcoholic hepatitis. It is possible to prevent HRS as a complication if SBP is urgently diagnosed and managed. Albumin infusion is the first way to be given and may helpfully delay HRS. Albumin infusion as an initial dose of $1.5 \mathrm{~g} / \mathrm{kg}$ body weight and repeated after 48 hours with a dose of $1 \mathrm{~g} / \mathrm{kg}$ body weight at the time of infection confirmed [51]. Salerno and colleagues reported that the complication of renal dysfunction (8\% vs. $31 \%$ ) and mortality (16\% vs. 35\%) were found to decrease among patients who received albumin infusion compared to patients who have not received albumin infusion [52]. Norfloxacin as antibiotic therapy can be considered in cirrhosis and ascites. Oral norfloxacin 400 $\mathrm{mg}$ /day in 12 months was related to decrease SBP progression (7\% vs. $61 \%$ ), lessen HRS progression (28\% vs. $41 \%$ ), while increasing survival rate up to three months (94\% vs. 62\%) and a year (60\% vs. 48\%) [30]. Tyagi and colleagues have investigated that pentoxifylline is beneficial or not; they found significant benefit with a $1200 \mathrm{mg} /$ day of pentoxifylline dose compared to placebo [54].

\section{CONCLUSION}

Hepatorenal syndrome is a complication of cirrhosis and portal hypertension. It remains a critical and life-threatening complication. Recent advances in understanding the pathophysiology of HRS have identified potential targets for novel diagnostic and therapeutic approaches. The first-line 
therapy is correction of volume expanders using albumin and vasopressin agents. Hence, the definitive treatment is still liver transplantation. However, given that organs remain a limited resource, further research into alternate therapeutic options will need to be explored.

\section{REFERENCES}

[1] P. Angeli and C. Merkel. "Pathogenesis and management of hepatorenal syndrome in patients with cirrhosis." Journal of Hepatology, vol. 48, suppl. 1, pp. S93-103, 2008.

[2] P.T. Pham, P.C. Pham, A. Rastogi, et al. "Review article: current management of renal dysfunction in the cirrhotic patient." Alimentary Pharmacology \& Therapeutics, vol. 21, no. 8 pp. 949-961, 2005.

[3] G.W. Neff, C.W. Duncan, E.R. Schiff. "The current economic burden of cirrhosis." Gastroenterology \& Hepatology, vol. 7, no. 10, pp. 661671, 2011.

[4] S. Scaglione, S. Kliethermes, G. Cao, et al. "The epidemiology of cirrhosis in the United States: a population-based study." Journal of Clinical Gastroenterology, vol. 49, no. 8, pp. 690-69, 2015.

[5] GBD 2013 Mortality and Causes of Death Collaborators. "Global, regional, and national age-sex specific all-cause and cause-specific mortality for 240 causes of death, 1990-2013: a systematic analysis for the Global Burden of Disease Study 2013." Lancet, vol. 385, no. 9963 pp. 117-171, 2015.

[6] W.A. Zatoński, U. Sulkowska U, M. Mańczuk, et al. "Liver cirrhosis mortality in Europe, with special attention to Central and Eastern Europe." European Addiction Research, vol. 16, pp. 193-201, 2010.

[7] F. Salerno, A. Gerbes, P. Ginès, et al. "Diagnosis, prevention and treatment of hepatorenal syndrome in cirrhosis." Gut, vol. 56, no. 9 pp. 1310-1318, 2007.

[8] F. Salerno, M. Cazzaniga, G. Gobbo. "Pharmacological treatment of hepatorenal syndrome: a note of optimism." Journal of Hepatology vol. 47, no. 5, pp. 729-731, 2007.

[9] American Association for the Study of Liver Diseases. "Management of adult patients with ascites due to cirrhosis: update 2012." American Association for the Study of Liver Diseases, pp. 1-96, 2012.

[10] R. Amathieu, A. Al-Khafaji, F.E. Sileanu, et al. "Significance of oliguria in critically ill patients with chronic liver disease." Hepatology, vol. 66, pp. 1592-1600, 2017.

[11] V. Arroyo, C. Terra, P. Ginès. "Advances in the pathogenesis and treatment of type-1 and type-2 hepatorenal syndrome." Journal of Hepatology, vol. 46, no. 5, pp. 935-946, 2007.

[12] E.A. Tsochatzis, J. Bosch, A.K. Burroughs. "Liver cirrhosis." Lancet, vol. 383, no. 9930, pp. 1749-1761, 2014.

[13] C. Francoz, F. Durand, J.A. Kahn, et al. "Hepatorenal syndrome." Clinical journal of the American Society of Nephrology: CJASN, vol. 14, no. 5, pp. 774-781, 2019.

[14] P. Balzaretti. "Treatment for hepatorenal syndrome in people with decompensated liver cirrhosis." Italian Journal of Emergency Medicine, vol. 9, no. 1, pp. 49-51, 2020.

[15] P. Angeli, P. Ginès, F. Wong, et al. "Diagnosis and management of acute kidney injury in patients with cirrhosis: revised consensus recommendations of the International Club of Ascites." Journal of Hepatology, vol. 62, pp. 968-974, 2015.

[16] V. Arroyo, P. Ginès, A.L. Gerbes, et al. "Definition and diagnostic criteria of refractory ascites and hepatorenal syndrome in cirrhosis. International Ascites Club.” Hepatology, vol. 23, no. 1, pp. 164-176, 1996.

[17] P.L. Bittencourt, A.Q. Farias, C. Terra. "Renal failure in cirrhosis: emerging concepts." World Journal of Hepatology, vol. 7, no. 21, pp. 2336-2343, 2015.

[18] E. Rodriguez, G.H. Pereira, E. Sola, et al. "Treatment of type 2 hepatorenal syndrome in patients awaiting transplantation: Effects on kidney function and transplantation outcomes." Liver transplantation: official publication of the American Association for the Study of Liver Diseases and the International Liver Transplantation Society, vol. 21, no. 11, pp. 1347-1354, 2015.

[19] V. Bodh, B. Sharma, R. Sharma. "Hepatorenal syndrome: a review into changing definition, diagnostic criteria, pathophysiology, and management." CHRISMED Journal of Health and Research, vol. 7, no. 2, pp. 83-89, 2020.

[20] T.D. Boyer, A.J. Sanyal, G. Garcia-Tsao, et al. "Predictors of response to terlipressin plus albumin in hepatorenal syndrome (HRS) type 1: relationship of serum creatinine to hemodynamics." Journal of Hepatology, vol. 55, no. 2, pp. 315-321, 2011.
[21] C. Fagundes, M.N. Pepin, M. Guevara. "Urinary neutrophil gelatinaseassociated lipocalin as biomarker in the differential diagnosis of impairment of kidney function in cirrhosis." Journal of Hepatology, vol. 57, no. 2, pp. 267-273, 2012.

[22] J.M. Belcher. "Acute kidney injury in liver disease: role of biomarkers." Advances in Chronic Kidney Disease, vol. 22, no. 5, pp. 368-375, 2015.

[23] A.A. Alsaad and H.M. Wadei. "Fractional excretion of sodium in hepatorenal syndrome: clinical and pathological correlation." World Journal of Hepatology, vol. 8, no. 34, pp. 1497-1501, 2016.

[24] A. Cardenas and V. Arroyo. "Hepatorenal syndrome." Annals of Hepatology, vol. 2, no. 1, pp. 23-29, 2003.

[25] F.J. Gifford, J.R. Morling, J.A. Fallowfield. "Systematic review with meta-analysis: vasoactive drugs for the treatment of hepatorenal syndrome type 1." Alimentary Pharmacology \& Therapeutics, vol. 45, no. 5, pp. 593-603, 2017.

[26] C. Sole, E. Pose, E. Sola, et al. "Hepatorenal syndrome in the era of acute kidney injury." Liver International, vol. 38, no. 11, pp. 18911901, 2018.

[27] S. Piano, H.H. Schmidt, X. Ariza, et al. "Association Between Grade of Acute on Chronic Liver Failure and Response to Terlipressin and Albumin in Patients with Hepatorenal Syndrome." Clinical Gastroenterology and Hepatology: The Official Clinical Practice Journal of The American Gastroenterological Association, vol. 16, no. 11, pp. 1792-1800, 2018

[28] M. Cavallin, P.S. Kamath, M. Merli, et al. "Terlipressin plus albumin versus midodrine and octreotide plus albumin in the treatment of hepatorenal syndrome: a randomized trial.” Hepatology, vol. 62, no. 2, pp. 567-574, 2015.

[29] L. Wang, Y. Long, K.X. Li, et al. "Pharmacological treatment of hepatorenal syndrome: a network meta-analysis." Gastroenterology Report, vol.8, no. 2, pp. 111-118, 2020.

[30] J. Fernández, M. Navasa, R. Planas, et al. "Primary prophylaxis of spontaneous bacterial peritonitis delays hepatorenal syndrome and improves survival in cirrhosis." Gastroenterology, vol. 133, no. 3, pp. 818-824, 2007.

[31] A.F. Carrion and P. Martin P. "Renal dysfunction in cirrhotic patients." The American Journal of Gastroenterology, vol. 114, no. 9, pp. 1407$1410,2019$.

[32] S. Mitzner. "Improvement of hepatorenal syndrome with extracorporeal albumin dialysis mars: results of a prospective, randomized, controlled clinical trial." Liver Transplant, vol.6, pp. 277$286,2000$.

[33] R. Bañnares, F. Nevens, F.S. Larsen, et al. "Extracorporeal albumin dialysis with the molecular adsorbent recirculating system in acute-onchronic liver failure: the RELIEF trial." Hepatology, vol. 57, no. 3, pp. 1153-1162, 2013.

[34] European Association for the Study of the Liver and European Association for the Study of the Liver. "EASL Clinical Practice Guidelines for the management of patients with decompensated cirrhosis." Journal of Hepatology, vol. 69, no. 2, pp. 406-460, 2018.

[35] T. Song, M. Rossle, F. He, et al. "Transjugular intrahepatic portosystemic shunt for hepatorenal syndrome: a systematic review and meta-analysis." Digestive and Liver Disease: Official Journal of the Italian Society of Gastroenterology and the Italian Association for the Study of the Liver, vol. 50,4 (2018): 323-330.

[36] P. Charilaou, K. Devani, R. Petrosyan, et al. "Inpatient Mortality Benefit with Transjugular Intrahepatic Portosystemic Shunt for Hospitalized Hepatorenal Syndrome Patients." Digestive Diseases and Sciences, vol. 65, no. 11, pp. 3378-3388, 2020.

[37] M. Martin-Llahi, M. Guevara, A. Torre, et al. "Prognostic importance of the cause of renal failure." Gastroenterology, vol. 140, no. 2, pp. 488-496, 2011.

[38] P. Palevsky, J. Zhang, T. O'Connor, et al. "Intensity of renal support in critically ill patients with acute kidney injury." New England Journal of Medicine, vol. 359, pp. 7-20, 2008.

[39] European Association for the study of the liver. "EASL clinical practice guidelines on the management of ascites, spontaneous bacterial peritonitis, and hepatorenal syndrome in cirrhosis." Journal of Hepatology, vol. 53, no. 3, pp. 397-417, 2010.

[40] Y. Chang, Q.Y. Liu, Q. Zhang, et al. "Role of nutritional status and nutritional support in outcome of hepatitis B virus-associated acute-onchronic liver failure." World Journal of Gastroenterology, vol. 26, no. 29, pp. 4288-4301, 2020.

[41] A. O'Brien and R. Williams. "Nutrition in end-stage liver disease: principles and practice." Gastroenterology, vol. 134, pp. 1729-1740, 2008.

[42] J.G. Park, W.Y. Talk, S.Y. Park, et al. "Effects of branched-chain amino acid (BCAAs) supplementation on the progression of advanced 
liver disease: a Korean nationwide, multicenter, prospective, observational, cohort study." Nutrients, vol. 12, pp. 1-11, 2020.

[43] J.R. Ospina and J.C. Restrepo. "Pathophysiology, diagnosis and management of hepatorenal syndrome." Revista Colombiana de Gastroenterologia, vol. 31, no. 2, pp. 141-147, 2016.

[44] J.G. Acevedo and M.E. Cramp. "Hepatorenal syndrome: update on diagnosis and treatment." World Journal of Hepatology, vol. 9, no. 6, pp. 293-299, 2017.

[45] P. Angeli, G. Garcia-Tsao, M.K. Nadim, et al. "News in pathophysiology, definition and classification of hepatorenal syndrome: A step beyond the International Club of Ascites (ICA) consensus document." Journal of Hepatology, vol. 71, no. 4, pp. 811$822,2019$.

[46] J. Chmielewski, R.J. Lewandowski, H. Maddur. "Hepatorenal syndrome: physiology, diagnosis, and management." Seminars in Interventional Radiology, vol. 3, no. 35, pp. 194-197, 2018.

[47] C. Alessandria, O. Ozdogan, M. Guevara, et al. "MELD score and clinical type predict prognosis in hepatorenal syndrome: relevance to liver transplantation." Hepatology, vol. 41, no. 6, pp. 1282-1289, 2005.

[48] B. Appenrodt, J. Zielinski, K.A. Brensing, et al. "Degree of hepatic dysfunction and improvement of renal function predict survival in patients with HRS type I: a retrospective analysis. European Journal of Gastroenterology \& Hepatology, vol. 21, no. 12, pp.1428-1432, 2009.

[49] C. Pant, B.S. Jani, M. Desai, et al. "Hepatorenal syndrome in hospitalized patients with chronic liver disease: results from the Nationwide Inpatient Sample 2002-2012." Journal of Investigative Medicine: The Official Publication of The American Federation for Clinical Research, vol. 64, no. 1, pp. 33-38, 2016.

[50] N. Goldaracena, M. Marquez, N. Selzner, et al. "Living vs. deceased donor liver transplantation provides comparable recovery of renal function in patients with hepatorenal syndrome: a matched case-control study." American Journal of Transplantation: Official Journal of the American Society of Transplantation and the American Society of Transplant Surgeons, vol. 14, no. 12, pp. 2788-2795, 2014.

[51] V. Arroyo and J. Fernández. "Management of hepatorenal syndrome in patients with cirrhosis." Nature Reviews Nephrology, vol. 7, no. 9, pp. 517-526, 2011.

[52] F. Salerno, R.J. Navickis, M.M. Wilkes. "Albumin infusion improves outcomes of patients with spontaneous bacterial peritonitis: a metaanalysis of randomized trials." Clinical Gastroenterology and Hepatology: The Official Clinical Practice Journal of The American Gastroenterological Association, vol. 11, no. 2, pp. 123-130, 2013.

[53] P. Tyagi, P. Sharma, B.C. Sharma, et al. "Prevention of hepatorenal syndrome in patients with cirrhosis and ascites: a pilot randomized control trial between pentoxifylline and placebo." European Journal of Gastroenterology \& Hepatology, vol. 23, no. 3, pp. 210-217, 2011. 